\title{
ARTÍCULOS
}

\section{EL ARCHIVO INDÍGENA Y EL RELATO DE SU HISTORIA EN LOS ANDES.}

\author{
Luis Miguel Glave \\ Instituto de Estudios Peruanos \\ Imglave@hotmail.com
}

Resumen: El estudio desarrolla la hipótesis acerca de que durante los siglos de dominación colonial, los indios de los Andes fueron construyendo un archivo en el que guardaron la memoria de sus luchas y reclamos y con ella, crearon un relato sobre su situación en la monarquía católica y las expectativas o programa sobre sus pretensiones dentro de ella. EI archivo se constituyó con los pedidos de mercedes, reclamos sobre cacicazgos, probanzas de linajes y servicios, memoriales de agravios, títulos de tierras, relaciones y cartas. De un universo muy amplio de documentos, que cubren distintas regiones del virreinato peruano, se establecieron correspondencias entre las gestiones y los discursos, los intercambios y la acumulación representativa de esa historia de lucha legal. Un caso desconocido y representativo, de Pedro Laureano de los Reyes sirve para ejemplificar la idea central.

Palabras clave: Memoriales, cacicazgos, memoria, archivo, lucha legal, sublevaciones indígenas.

Tittle: THE INDIGENOUS ARCHIVE AND THE STORY OF ITS HISTORY IN THE ANDES.

Abstract: The study develops the hypothesis that during the centuries of colonial domination, the Indians of the Andes were building an archive in which they kept the memory of their struggles and claims and with it, they created a story about their situation in the Catholic monarchy and the expectations or program about his claims within it. The archive was created with requests for grants, claims on chiefdoms, evidence of lineages and services, memorials of grievances, land titles, relationships and letters. From a very wide universe of documents, covering different regions of the Peruvian viceroyalty, correspondences were established between the negotiations and speeches, exchanges and the representative accumulation of that history of legal struggle. An unknown and representative case, of Pedro Laureano de los Reyes serves to exemplify the central idea.

Keywords: Memorials, chiefdoms, memory, archive, legal struggle, indigenous uprisings.

Desde los primeros años de la invasión, el engranaje de la elaboración de documentos y la tramitación administrativa y legal que los demandaba, se echó a andar como uno de los pilares del nuevo régimen que se creaba ${ }^{1}$. Lo que valía para los españoles, también lo hacía para los indios. Rápidamente, ellos se avocaron a

1 BRENDECKE, Arndt. Imperio e información. Funciones del saber en el dominio colonial español. Madrid: Iberoamericana; Frankfurt am Main: Vervuert, 2012.

Recibido: 08-07-2020

Aceptado: $12-08-2020$

Cómo citar este artículo: GLAVE, Luis Miguel. El archivo indígena y el relato de su historia en los Andes. Naveg@mérica. Revista electrónica editada por la Asociación Española de Americanistas [en línea]. 2020, n. 25. Disponible en: <http://revistas.um.es/navegamerica>. [Consulta: Fecha de consulta]. ISSN 1989-211X. 
elaborar sus documentos y a presentarlos para litigar, reclamando derechos o protestando por la violación de las normas que poco a poco iban también conociendo. Necesitaron ayuda de letrados, pero ellos mismos empezaron a apropiarse de la palabra escrita, de distintas maneras, a veces colectivamente. Esa cultura escrita y legal se fue archivando en las instituciones hispanas, tanto en los reinos de Indias como en la metrópoli. Esto es algo conocido y estudiado ${ }^{2}$. Lo es menos que los indios fueron creando también, sin institucionalizarlo, un archivo que guiara sus trámites, guardara su memoria $y$, en un extremo, informara sus movilizaciones culturales y políticas e incluso sus sublevaciones. El trabajo por descubrir ese archivo es una tarea pendiente. Para rastrearlo es necesario recurrir al archivo institucional hispano, escarbar en él ${ }^{3}$.

\section{Naturaleza del archivo indígena}

No fue que lo hicieran sin entrenamiento. En medio de una febril situación de inestabilidad, donde todos los actores buscaban afianzarse en ese inédito mundo que estaban creando, los procesos administrativos y judiciales convocaban testigos que declararan acerca de los hechos que se juzgaban o de las formas y relaciones socio económicas que se iban implementando. Para las declaraciones que se requirieron a los indios, particularmente a su señores étnicos o principales, se les pidió que acudieran a su memoria 4 . Se fue así tejiendo un relato del pasado lejano y de la rápida mutación que la imposición colonial significó. Buscando afianzar poderes o disputarlos, los jefes étnicos se enfrascaron en largas disputas entre ellos por los puestos principales de mando, pero también enfrentando a sus encomenderos. Para ello declararon en base a sus recuerdos, incluso se aportaron quipos para "documentar" su historia más reciente. Todo fue dando como resultado expedientes que se guardaban en archivos familiares y locales. Las cédulas de encomienda y las tasas de tributos se guardan celosamente en cajas comunales que eran germen de archivo. Lo mismo pasó con las composiciones de tierras y los títulos de propiedad. Muchas veces circularon entre una región y otra, o entre un linaje y otro. Se atesoraban cédulas reales, probanzas con declaraciones de los más mayores. Se construyó, sin un plan predeterminado e incluso sin ser conscientes de

2 Ver, por ejemplo: LIENHARD, Martin. Testimonios, cartas y manifiestos indígenas. Caracas: Biblioteca Ayacucho, 1992; RAPPAPORT Joanne y CUMMINS, Tom. Más allá de la ciudad letrada: letramientos indígenas en los Andes. Bogotá: Editorial Universidad del Rosario, 2016; NOACK, Karoline. Los caciques ante el notario: transformaciones culturales en el siglo XVI. EN: NOEJOVICH CHERNOFF, Héctor (ed.). América bajo los Austrias: economía, cultura y sociedad. Lima: Pontificia Universidad Católica del Perú, 2001, pp. 199-200.

${ }^{3}$ BURNS, Kathryn. Making Indigenous Archives: the Quilcaycamayoq in Colonial Cuzco. En: RAMOS, Gabriela and YANNAKAKIS, Yanna (eds.). Indigenous Intellectuals. Knowledge, Power and Colonial Culture in México and the Andes. Durham: Duke University Press, 2014, pp. 237-260. Rosario NAVARRO GALA, Rosario. El libro de protocolo del primer notario indígena (siglo XVI). Cuestiones filológicas, discursivas y de contacto de lenguas. Madrid: Iberoamericana-Vervuet, 2015. ESTRUCH, Dolores y OYARZABAL, María Cecilia. Indígenas y archivos. Entre el acervo documental y las herramientas metodológicas. El caso de Jujuy colonial. Revista Historia y Justicia. 2016, n. 7, pp. 95121. En Yucatán ver, por ejemplo, CUNILL, Caroline. Archivos en los Pueblos Mayas de Yucatán y la Construcción de una Memoria Legal (siglo XVI). Fronteras de la historia. 2016, n. 21/1, pp. 14-39.

4 HONORES, Renzo. Los caciques y las pruebas: El uso de las testimoniales en las disputas por cacicazgos en la Audiencia de Lima, 1550-1610. En: Tucumán: XI Jornadas Interescuelas/Departamentos de Historia [en línea]. Departamento de Historia, Facultad de Filosofía y Letras. Universidad de Tucumán, 2007. Disponible en <http://cdsa.aacademica.org/000-108/924>. 
ello, un archivo y con él, un conocimiento y un relato.

Es conocido el importante papel de los curacas o caciques en el funcionamiento de la sociedad, la economía y la política de la época colonial andina. Fueron piezas fundamentales en el engranaje que el estado colonial tenía para obtener recursos de las poblaciones indias mayoritarias del reino. Sin ellos no era posible que el sistema funcionara. Por eso, el puesto formal e institucional de cacique gobernador era objeto de enconadas disputas de poder, tanto local como a nivel regional y estatal. A nivel local, influían en el nombramiento del gobernador indio las familias cacicales, tanto las de linajes de sangre como la de indios exitosos en sus relaciones económicas y políticas. También lo hacían los interesados en la mano de obra y los recursos locales, ya que no era esa, ni ninguna sociedad, un armario de compartimientos estancos. Así, el puesto también tenía que ver con el juego de poder local en el que tomaban parte corregidores, encomenderos, hacendados y comerciantes, amén de blancos entre indios que proliferaban a pesar de las prohibiciones que la corona pretendía imponer para que no se mezclaran las repúblicas. Finalmente, también influía la política estatal, la filosofía regia del poder ejercido sobre los vasallos indios, se explayaba en normas referidas tanto al nombramiento de los jefes nativos, como de toda la escala de autoridades que dieron lugar al nacimiento de las comunidades indias, refundadas sobre los viejos ayllus y aldeas dispersas en las que se había organizado la economía campesina precolonial. Se pretendió acabar con las formas políticas complejas que remitían a esa época y a los poderes que entonces se manifestaron. Pero a la vez, el rey no podía dejar de reconocer los derechos de los señores de indios y señores naturales a cuya cesión de señorío debía el reconocimiento de la posesión del reino y el vasallaje sobre los hombres. Por eso también existieron curacas de sangre, que subordinaron sus antiguas formas de herencia al conjunto de símbolos y patrones de la sucesión castellana medieval. La resultante fue una compleja red de combinaciones que podían tener un resultado dominante colonial u ocultar viejas formas -siempre alteradas por el tiempo y las luchas- de legitimidad cultural nativa.

Sabemos ahora mucho de estos linajes cacicales, de las formas de la herencia, de la legislación y la práctica coloniales sobre el ejercicio del mando indio. Hubo linajes hereditarios que se erigieron en depositarios de memoria local y de ejercicio del poder desde el mantenimiento de elementos culturales pre coloniales. Muchas veces entraron en conflicto con el poder colonial o con otros mecanismos de control social, otras veces éstos los subsumieron. A la vez, hubo un ejercicio de función colonial que bien podía ser ejecutada por el cacique gobernador, que provenía de las familias nobles o ennoblecidas de los linajes ancestrales, 0 por caciques sin herencia que se reclutaban entre esas élites indias y entre los naturales con éxito económico en el manejo de los recursos y en la incursión mercantil. Y existió también un cabildo indio que en muchos casos actuaba en reemplazo de las jefaturas étnicas extinguidas en el proceso de colonización mercantil de la población campesina.

Como quiera que sea, el tema de la sucesión en los cacicazgos fue un escenario de conflicto y también un terreno de creación y recreación de memorias locales. Esto incluyó también la legitimación de linajes que permitía librarse del tributo y acceder a 
oficios. Poco a poco se fue abriendo también un campo de memoria y de política india general en la que la figura de los ancestros más poderosos, como los incas paradigmáticamente, pero también los mochicas y chimús, se consolidaron como los depositarios de la historia nativa y de las expectativas de esa nueva colectividad indio colonial. Esto significó una serie de alianzas cacicales, a través de los matrimonios entre miembros de linajes distintos y propendiendo las más de las veces a incorporar algún ancestro que los vinculara con los incas. Así, los linajes de caciques se tradujeron en una forma de creación de una nueva colectividad india, una nueva memoria política, una etnogénesis que a la vez vinculaba de nuevas maneras a los grupos culturales y lingüísticos que existieron previos a la imposición colonial ${ }^{5}$.

No todos los actores que encarnaron este proceso fueron gobernadores efectivos de los pueblos y repartimientos indios o representantes naturales de provincias de mayor envergadura, existieron otros cargos que desempeñaron con reconocimiento de la corona como el de alcaldes mayores, alguaciles, capitanes de mita, veinticuatros de cabildos urbanos o de cofradías. También hubo escalones intermedios pero importantes como el de traductores, escribanos, contadores, cantores y un largo etcétera. Junto a la representación de los pueblos de indios y las provincias campesinas, aparecieron los indios urbanos. Las ciudades fueron también escenario de esta etnogénesis. Cierto que era en esa forma civilizatoria donde se incubó la sociedad criolla que tendió a subordinar y absorber a los indios, pero no es menos cierto que allí también se fraguaron formas de resistencia cotidiana indígena, de contactos políticos que limaban las asperezas y rencillas que caracterizaron una sociedad atomizada, que permitían un encuentro entre diversos grupos culturales y diversas lenguas. Hubo estos escenarios urbanos indios en muchos puntos del virreinato, pero destacaron cuatro por su trascendencia e importancia: Quito, Potosí/La Plata, Cuzco y Lima. Salvo Cuzco que estaba llamada a serlo, se trataba de las sedes de las Audiencias. Fue sin embargo en la capital donde se procesó el nacimiento de estas nuevas formas de alianza india.

En los tribunales de la Audiencia de Lima, en las salas de los acuerdos económicos y de justicia que presidía el virrey, por pleitos civiles y criminales o por simples tratos mercantiles, hubo presencia de un grupo de indios cabildantes que fue tejiendo un nuevo modo de actividad política colonial. Transformaron los jirones de la antigua aristocracia india de la zona de la ciudad y se vincularon con las familias cacicales de los valles que formaban su hinterland. Recibieron a nobles indios de diversas regiones y particularmente de la región norteña de la costa. Se comunicaron con los jefes de la sierra central y sur central, con los del sur y con los del altiplano del Collao. Se convirtieron en procuradores permanentes y representantes de los indios del reino. Cuando fue necesario, enviaron emisarios a la misma corte del rey en España. Al principio esos viajes fueron gestiones casi personales que adquirieron la forma de agencia india, pero luego se fue casi institucionalizando, hasta el nombramiento de don Vicente Morachimo como

\footnotetext{
5 JURADO, M. Carolina. Descendientes de los primeros. Las probanzas de méritos y servicios y la genealogía cacical, Audiencia de Charcas, 1574-1719. Revista de Indias. 2014, n. 261, pp. 387-422. CASTRO FLORES, Nelson. Estrategias familiares, prácticas jurídicas y comunidad de memoria. Los descendientes de Tito Alonso Atauchi y Viracocha Inca en Charcas, siglos XVI-XVIII. Estudios Atacameños. 2019, n. 61, pp. 177-198.
} 
procurador general de los indios del Perú en España en la segunda y tercera décadas del siglo XVIII. Un conjunto de cartas y documentos se fueron agrupando para "sustanciar" sus demandas, pertenecieron a su archivo ${ }^{6}$. Esa práctica política era una resultante de anteriores intentos de organización.

\section{La gestión del archivo indígena en la lucha político legal del siglo XVII}

En el siglo XVII, en el contexto de la visita de desagravio de los indios y de la famosa polémica del licenciado Juan de Padilla y Diego León Pinelo de 1657, se produjo una campaña de memoriales concertados. Se trató de un proceso que hemos denominado la gestación de un programa político para la nación indiana o índica. Diferentes indios, el 19 de enero 1662 encabezados por Cristóbal Ticsi Runa Atoc y Jerónimo Limaylla, presentaron un primer memorial ${ }^{7}$. Ese fue un antecedente de otros. Los caciques y gobernadores de diferentes pueblos elaboraron otro el 28 de noviembre de 1662. A raíz de la junta que la corona ordenó convocar por la carta de Padilla, se quejaron de que, aunque allí se había ventilado el tema de las vejaciones, denunciaban las que venían sufriendo a pesar de esa instancia. El colectivo indio hablaba en su instancia del gran memorial que don Cristóbal Ticsi Runa Atoc. Este indio principal parece haber encabezado el movimiento, bajó de su provincia de Tarama (Tarma) y quiso hacer una gestión sobre los diezmos y los agravios que los indios recibían por ello, por lo que había conseguido una ejecutoria del Consejo, enviando memoriales con los remedios propuestos al respecto, no lo pudo verificar y murió en la demanda (fin de setiembre). Los memorialistas narraron cómo muchos caciques habían ido a Lima a representar sus trabajos, seguros de enternecer al rey, pero se les impidió este recurso y uno de ellos, que había de ir a la corte en demanda de esto, don Cristóbal Ticsi Lunato -el mismo Ticsi Runa Atoccacique principal y gobernador de la provincia de Chinchaycocha, "estando prevenido para escapar como pudiese, siguiendo este viaje habrá dos meses que murió", es decir, hacia fines de septiembre, aumentando la desesperación de los indios pues era "capaz y de buena recomendación". En su nombre se dio el memorial y anunciaban que "se dará orden" para que vaya a manos del soberano ${ }^{8}$.

El "gran memorial" de Ticsi proponía el establecimiento de una doctrina de jesuitas visto el éxito y favor de los indios en Juli; que no se provean los corregidores en el reino porque luego lo que gastan lo sacan de los indios y no cumplen las cédulas contra los tratos; que se asegure el pago a los defensores de los indios; que

\footnotetext{
${ }^{6}$ GLAVE, Luis Miguel. Memoria y memoriales: la formación de una liga indígena en Lima (1722-1732. Diálogo Andino. 2011, n. 37, pp. 5-24.

7 El documento, como el resto de memoriales que analizaremos en las páginas siguientes, se encuentran en Archivo General de Indias, Lima 17. El descriptor del legajo dice "Decretos originales correspondientes al distrito de la Audiencia de Lima (1663-1673)" pero el grueso de la documentación se ubica en la coyuntura de debates que analizamos y contiene la mayoría de los memoriales de los que damos cuenta. He analizado este material en GLAVE, Luis Miguel. La gestación de un programa político para la nación indiana (1645-1697). Revista Andina. 2018, n. 56, pp. 9-99.

${ }^{8}$ Hay referencia a este curaca por parte de MATOS, Mar y ORTEGA, Moisés. Acolla informes para el pueblo y para el tiempo. Jauja: Holckon editores, 1999. Lo citan ROBLES, Román y MARTíNEZ, Melinda. Sociedad y tradiciones en el valle de Yanamarca. Revista de Antropología (UNMSM). 2004, núm. 2/2, pp. 191-250. Compró la hacienda Yanamarca en la campaña de composiciones en 1645, al parecer tierras realengas donde había habido una fundición y luego las vendió a los dominicos en 1650.
} 
se junten las doctrinas y los anexos; que se hagan padrones, se vea lo de los forasteros, no se les cobre el peso ensayado por los curas, etc. Como muchos de estos memoriales, éste empieza y termina literariamente, al gusto y uso de la época. Firman: Carlos Apoalaya, cacique gobernador de Hananguanca en Xauxa; Gerónimo Limaylla, del repartimiento de Luringuanca, Xauxa; Lope Joseph Mayta Capac Atauche Inga, cacique principal y gobernador de la provincia de Omasuyo en el pueblo de Copacabana; Cristóbal Yamque, cacique principal y gobernador de la provincia de Vilcasguaman, en los pueblos de Guamanquiquia, Carapo y Guambo este Cristóbal Yanque de Huamanquiquiquia o Guamanquiquia hizo poco después el 29 de noviembre 1662 otro memorial de agravios- Melchor Ataoche Topa Cusirimachi Inga, principal cacique y gobernador de la ciudad de Arequipa; Jacinto Nina Gualpa, cacique de la provincia de Vilcasguaman y Pedro Salvador Tito Qoaque de Cullaruni, cacique y gobernador del pueblo de Oropesa. Este elenco era la vanguardia de los caciques organizados.

Juan Guaynapiric, cacique de los Margos en Tarama, el mismo 29 de noviembre de 1662 del memorial de Yanque, presentó otro memorial. Hacía dos años que asistía en Lima "tratando de la defensa de los indios a él sujetos" por las violencias que recibían de los religiosos de la orden de la Merced que fundaron obrajes, tornos y telares, siendo patrón de las oficinas el padre Juan Bara del que ya se había hecho denuncia y por real cédula se había mandado que no se le dejase asistir en esa doctrina. Por más tiempo de diez años había fomentado el obraje de Yaromayo, remitiendo más de 40,000 varas de ropa todos los años diciendo que eran de su religión, "obradas con la opresión, sudor y sangre de los miserables indios". Usaba su mano de cura y lo asistían cuatro religiosos. Denuncia que haría año y medio pasando el puente del río de la ciudad, a la hora de la oración y dirigiéndose a su casa, lo hirieron en la garganta, donde le pusieron 11 puntos que fue un milagro se salvase sin que precediese otra causa que el tratar la defensa de sus indios. No se atemorizó por eso, sino que con nuevos bríos siguió su defensa tan justa. Con el caso de Ticsi Runa Atoc, el de Guaynapiric revela lo cruento que era el enfrentamiento que los memoriales estaban denunciando.

Otro memorial de varios principales, entre otros Diego Lovo (Lobo) cacique de Olmos -veremos lo que significa este Lobo- y Carlos Apoalaya vuelve sobre memorial que se remitió en nombre de Cristóbal Tissi Runato (Ticsi Runa Atoc). Esta nueva instancia india fue fechada en Lima el 29 de noviembre de 1662 es decir, EL MISMO DIA. El escrito, que contenía mucha parte de los trabajos y miserias de los indios, lo había dispuesto y dictado el licenciado Alonso de Quesada presbítero, con las grandes noticias y experiencias que tenía de lo que padecían los indios y con el celo de la defensa que les hacía; porque había padecido los trabajos que debían constar en el Consejo de Indias a donde se remitían. Para que tengan recomendación ante la católica piedad el ánimo y buen deseo de este sacerdote, le representan ser suya la obra en todo lo que contiene "y sobre que tiene escrito un libro dedicado a Vmagd. El cual presentó ante el virrey Conde de Santisteban pidiendo licencia para imprimirle para que llegase a manos de VM y de sus consejos". No saben por qué se ha dilatado esto, pero presumen que se le remite manuscrito. De uno y de otro le dan cuenta para que sepa lo que cabe en el celo de este sacerdote y que el memorial referido que va en el nombre de Ticsi es suyo. 
Melchor Ataoche Topa Cusirimache Inga escribe desde Arequipa a 20 febrero 1662. Merece atención también. Estos son el corpus de memoriales que he examinado en oportunidad anterior y que aquí recordamos para añadir otras ramas de la campaña. Todas además acompasando una acción que llevaron adelante en la propia corte madrileña a través de un memorial de fray Juan de la Madre de Dios recoleto de San Agustín de 27 de junio de 1663 y el de Antonio Collatopa que pedía se favorezca a los indios del 17 de marzo de 1664. Así, varios caciques y nobles indios, entre los cuales Ataoche Topa Cusirimache Inga de Arequipa, escribieron otro memorial en Lima, sin fecha, pero de 1663. En todo nos remitimos, decían, al informe que hiciere a VM don Antonio Díaz de las Cuebas Collatopa descendiente de los hijos de Guaynacapac que con riesgo de la vida dejando su mujer e hijos va en nombre de todos a los pies de VM. Es decir, saben que Collatopa está en Madrid, aunque no ha presentado todavía su memorial. Como resultado de toda esta agitación se dio Real Cédula de 6 de agosto de 1664 mandando se forme otra Junta de Desagravio que sesione dos veces por semana sólo sobre el particular.

En un grueso cuadernillo que se conserva en el legajo que contiene la parte sustancial de estos memoriales, se encuentra el de Gerónimo de Limaylla, sobre la sucesión del cacicazgo que pretendía en 1664. Es muy probable que estuviera de agente de los curacas por entonces. Por ejemplo, al parecer ayudó a la presentación del memorial de Chudin, un cacique de la región de la Audiencia de Quito y el de Juan Crisóstomo Chilingano Atahualpa Inga que viajó en nombre de los indios de Huamanga, firmado este en noviembre de 1662 y que se vio ese 1664. Esta campaña se respondió en la corte con una orden para que se vuelvan a su tierra el 21 de agosto de 1664: Limaylla, Collatopa, Juan Crisóstomo Atahualpa, Nicolás Tolentino y Cristóbal Chudin Bamon. Chudin, cacique de Chongon pedía gubernatura de Santa Elena por los servicios de su padre. Tolentino, cacique de Santiago de Chuco seguía en Madrid en 1666. Y Diego Sánchez Macario, cacique de Pillao en Tarma pidió amparo para sus indios en 1666 pero le respondieron secamente que ya estaba formada la Junta mandada instalar al efecto. Aunque en la práctica no fueron eficientes las formas institucionales que la corona mandó establecer para absolver esta andanada de quejas, lo cierto es que la campaña de los indios andinos obtuvo resultados. Y esa campaña, dejo un poso de memoria y una documentación que se archivó.

Mención aparte merece la campaña que encabezó Gabriel Fernández Guarache. Es otra coyuntura o espacio, pero coincide con el proceso político general. Primero en la agitación conjunta hasta 1660 y luego el "memorial grande" en $1661^{9}$. No fue esta la única acción conjunta de los capitanes y caciques de la mita de Potosí; en 1660, nuevamente a instancias de don Gabriel, hicieron la pieza más sentida que enviaron directamente al rey ${ }^{10}$. Representaron muy por menor los

\footnotetext{
${ }^{9}$ Hemos presentado y trascrito este memorial y el contexto en CHOQUE CANQUI Roberto y GLAVE, Luis Miguel. Mita, caciques y mitayos: Gabriel Fernández Guarache. Memoriales en defensa de los indios y debate sobre la mita de Potosí (1646-1663). Sucre: Archivo y Biblioteca Nacionales de Bolivia, 2012.

${ }^{10}$ AGI Charcas 266, núm. 42. Memorial de los caciques y principales de las provincias que mitan, Potosí 23 de enero de 1660. Hay publicación por LÓPEZ BELTRÁN, Clara Estructura económica de una sociedad colonial: Charcas en el siglo XVIII. La Paz: CERES, 1988, pp. 271-275.
} 
agravios, molestias, vejaciones y afrentas que recibían ellos y los demás indios sobre el entero de la mita de Potosí por parte del corregidor de aquella villa y de otras justicias y de los mineros, ponderando la desesperación que los llevaba a apartarse de la enseñanza de la santa fe y ahorcándose y dejándose morir muchos Suplicaban que compadeciéndose de vasallos tan indefensos y trabajadores se les proveyese de algún alivio y defensa.

\begin{abstract}
"Los caciques y principales de las provincias que mitan a esta villa en que estamos sirviendo a VM parecemos humildes a sus reales plantas representando la opresión en que vivimos con todos los demás de nuestra nación por sólo obedecer lo que VM tiene mandado que es venir a trabajar a este cerro en la saca de metales y su beneficio".
\end{abstract}

Se trata de un documento típico de lo que podemos llamar un discurso cacical que se materializaba en memoriales, dictado en nombre de la nobleza indígena ("y nosotros oprimidos y afrentados, habiéndonos Dios hecho nobles y VM mandado por tantas cédulas se nos guarden nuestros fueros..."), reclamando por las afrentas que recibían. Y señalando sus aliados: "Envió el Conde de Alva virrey al obispo de Santa Marta al repartimiento general de la mita, remedio del mal uso de los indios de faltriquera... hemos respirado después que vino...". Nuevamente ponderan el apoyo de uno de los Protectores que dejó huella: "Enviónos el virrey un protector que es don Cristóbal de Laredo y Treviño caballero de la orden de San Jorge, que nos ampara y defiende que ha muchos años no tenemos otro, porque antes han sido contrarios y para prueba baste que cuantos jueces han salido de esta villa contra nosotros, han sido a petición del Protector coligándose con los azogueros para que siendo a petición del Protector en nombre de los capitanes enteradores, sean a costa nuestra y no de los azogueros como VM manda, ni de los corregidores como el gobierno tiene ordenado, para lo cual usan de apremios extraordinarios para obligarnos a enterar los indios que faltan, porque aprobemos las peticiones de jueces que hace el Protector, de quien recibimos ordinariamente agravios pidiéndonos plata por lo que obra, mas el presente procede con mucha justificación y es buen cristiano haciendo nuestras causas sin recibir cosa alguna, teniendo por defendernos muchos pesares con el corregidor y los interesados". La carta se envió cuando todavía no había muerto el enviado del virrey para solucionar los conflictos, el obispo Francisco de la Cruz.

Firmaron la pieza, este otro activo grupo de caciques, que se denominaron "los caciques del Perú en Potosí": Don Gabriel Fernández Guarache, cacique del pueblo de Jesús de Machaca y capitán general de la mita de la provincia de Pacajes; Juan Taguallu, cacique del pueblo de Asanaques; Felipe Chambilla, cacique del pueblo de Zepita y capitán general de la provincia de Chucuito; Juan Chuquimamani. capitán enterador; Felipe Challapa, cacique del pueblo de Challacollo; Melchor Chuquiguanca, cacique del pueblo de Azángaro; Francisco Martín Yave, capitán del pueblo de Colquemarca; Pedro Hyco, cacique de Chayanta; Rafael Gallegos, cacique del pueblo de Aymaya; Miguel Ayavire, cacique de Toledo; Felipe Mendoza, cacique de Acora; Claudio Ignacio, cacique de Yole; Felipe Chambilla, cacique de Pomata; Diego Alanoca; Pedro Fernández Guarache, gobernador del pueblo de Jesús de Machaca; Sebastián Cabana, cacique de Andamarca; Diego Mamani, cacique de Arapa y Diego Menacho, gobernador de Caquiaviri. 
Es la época de los más largos memoriales contra la mita presentados por Gabriel Fernández Guarache, entre 1661-1663 y de las maniobras legales que hizo hábilmente, en medio de los enfrentamientos armados en la región, el curaca Bartolome Tupac Hallicalla (1668) ${ }^{11}$. Pero, junto con los papeles, algunos grupos tomaron el camino de los hechos, como en Songo, en 1664, donde los indios se volvieron a sublevar dirigidos por Alonso Palluri. Fue entonces que se presentó lo que de alguna manera se podría considerar un intento de sublevación, como lo consideró la Audiencia de Lima en 1666 y 1667. Todo indica que hubo reuniones, pero la traición fue abortiva. El traidor fue Diego Lobo.

Lobo no fue uno más entre este grupo de indios políticos y escritores. Con letra preciosa, escribió un memorial de un folio por ambos lados. Se decía capitán don Diego Lobo, indio principal del pueblo de Santo Domingo de Olmos, encomendado en la corona, en el corregimiento de Piura la vieja y residente en la provincia de Caxamarca, gobernador de los indios forasteros que pagan quintos a la Real Hacienda. Contaba su servicio en la delación de 1666. Que estaba en Lima siguiendo ciertos pleitos y "por noticioso de algún curso de papeles, me eligieron los complicados por caudillo de este levantamiento". Viendo la ocasión, con licencia secreta del Real Acuerdo procedió con legalidad y por sus avisos se les castigó. Le dieron 1,000 pesos con los cuales tuvo apenas para aviarse al reino de Tierra Firme con intención de llegar a la corte del rey. En Tierra Firme encontró al virrey Conde de Lemos al que le presentó sus despachos y éste le reconoció y mandó volver al Perú con promesa de hacerle premio competente. Pero "por dictamen de malos afectos se entregó al olvido la promesa y mis servicios". El virrey le dijo que acudiera al rey, que no había indios para encomendarle, pero Lobo no había podido hacerlo por la pobreza en la que había quedado con su familia. Por eso acudía con este escrito al Rey como última instancia y proponiendo lo peligroso que fue su servicio y lo importante que es patrocinar estas actitudes para el futuro, pedía que se entendiera que su merced de los mil pesos fuera por los años de su vida, situados en la caja de Trujillo. Pedía también le encomiende los indios libres yanaconas que pagaban quinto en Caxamarca de los que era entonces capitán de infantería y su gobernador y como tal los defiende. Atrás dice: Caxamarca, no trae fecha ni año. D. Diego lobo. Recibida con aviso en 27 de julio de 1688. Cámara. La ambición de Lobo, reconocido traidor, era muy grande, como el desdén con el que se le recibió.

Hubo otra carta de Lobo, igualmente de bella letra que se fechó en Caxamarca a 26 de abril de 1685, sobre lo mismo. Se recibió el 29 de julio de 1688, es decir, dos días después de la otra. Ambas se juntaron y se respondieron en el consejo de 22 de setiembre de 1688. El fiscal opinó que si lo que refiere es verdad, conviene darle algo más a este indio para que sea un ejemplo. Pero esta vista fiscal lleva fecha de 10 noviembre de 1690, dos años después de recibidas las cartas. No dice lo que se acordó. Decía Lobo que a otros que han hecho servicios menores, como el que delató "un torbellino particular" cuando gobernaba el Conde de Malagón percibe al presente sueldo de las cajas reales. Que él no tiene nada sino pobreza y lo que ganó fue "el mal afecto y mortal antipatía de mis hermanos los indios, de cuyas violencias milagrosamente he zafado la vida".

11 GLAVE, Luis Miguel. Un curacazgo andino y la sociedad campesina del siglo XVII. La historia de Bartolomé Tupa Hallicalla, curaca de Asillo. Allpanchis. 1989, n. 33, pp. 11-39. 
Lobo tenía un pequeño archivo personal. Presentó también una certificación del Acuerdo Real donde lo premiaban y donde constaba el resumen de su servicio. Sin novedad, acusa a Gabriel Manco Capac que sí condujo un intento de asonada en Jauja y menciona a Ordóñez y a Juan Bautista de Jesús que ya habían sido ajusticiados, todo conforme a lo relatado por la Audiencia en un largo informe ${ }^{12}$.

Pudo tratarse, como el caso de Lobo, de un currículum lleno de servicios, más que de un linaje y una pequeña historia, pero unos y otros, fueron desarrollando el discurso de la "entrega pacífica" o contractual, por la que los Incas cedieron el reino al rey de España. Esto se fue construyendo como discurso, lo mismo que la versión de ser ellos los más leales vasallos del rey. En todo el relato, el principio del honor guiaba los postulados de los reclamos. Esa fue la piedra de toque de los memoriales del mestizo Juan Núñez Vela, presbítero peruano que en la corte luego de largas negociaciones, obtuvo que se reconociera la hidalguía de los indios nobles. Núñez Vela mismo en sus memoriales hizo una pequeña historia de su linaje. Cada probanza o cédula obtenida era a su vez un archivo de gestiones y documentos arrancados a la administración. Unas décadas después, ya promulgada la real cédula de los honores, ganada en Madrid por el religioso descendiente de los incas Juan Núñez Vela de Ribera, la campaña por que se cumpliera, que se juntó con otra coyuntura de ataque a los recursos indígenas, se formó en Lima una "liga indígena" que tenía su representante en Madrid a don Vicente de Morachimo. En los cajones de los caciques que la formaron, se guardaban varias de las piezas que hemos referido en los párrafos precedentes. Tenemos ya estudios que hablan de las gestiones que, al calor de este largo proceso, llevaron adelante miembros de la nobleza indígena ${ }^{13}$. Presentamos ahora las que llevó adelante un desconocido personaje perteneciente a este escalón indios nobles urbanos.

\section{Pedro Laureano de los Reyes Macharé y las redes de nobles indígenas y descendientes incas en Lima antes de la gran rebelión de los Andes}

Hace algo más de una década, buscando documentos que me permitieran estudiar las formas en las que la memoria indígena se fue conformando durante el periodo colonial, me topé con un legajo del Archivo General de Indias que contenía los expedientes que el Consejo de Indias había seleccionado de aquellos pretendientes a la descendencia inca que aspiraron o podían aspirar a ser sucesores del llamado Marquesado de Oropesa, el feudo que el rey concedió al inca Sayri Tupac para que se aviniera a dar la obediencia y la paz a la corona y que luego de un par de sucesiones, había quedado vacante. Se trataba de un elenco de documentos que hacían alusión a quienes habían mostrado alguna documentación que diera cuenta de su linaje entroncado con alguna rama de las familias de los señores naturales del reino ${ }^{14}$. Estas instancias probatorias de genealogías que de alguna manera se remontaban o entroncaban con los incas, son relativamente abundantes en los archivos y algunas son muy conocidas. Las hubo muy bien

\footnotetext{
${ }^{12}$ Más sobre Lobo y los sucesos en GLAVE, Luis Miguel. La gestación... Op. cit.

${ }^{13}$ GLAVE, Luis Miguel. Memoria y memoriales... Op. cit. y GLAVE, Luis Miguel. La gestación... Op. cit.

$14 \mathrm{AGI}$, Indiferente 1613. Descriptor: Encomiendas concedidas a descendientes de los Incas. Contenido: Encomiendas, mercedes y privilegios concedidos a las familias descendientes de los Incas, y a los herederos de D. Pedro Pizarro, Marqués de Valverde y Caracena. Pero dentro el envoltorio del Consejo dice: Familia y descendientes de los Yncas.
} 
elaboradas y totalmente ficticias como la de un Blas Tupac Amaru que murió regresando de España con una mera carta de recomendación poco antes de la gran rebelión de los Andes de 1780 y desde luego, el propio José Gabriel Condorcanqui desempeñó activo rol en la lucha por la pretensión a ser considerado el mejor y más legítimo inca descendiente: el "tronco principal" como se decía en sus edictos ${ }^{15}$. Pero entre los incluidos en el aludido legajo, figuraba un descendiente desconocido que no había aspirado a mucho, pero que había logrado tejer un árbol genealógico sorprendente y paradigmático.

Con Real orden de 23 de julio de 1776 se remitió al Consejo de Indias el "Expediente sobre la declaración de fiel vasallo y persona noble que solicita D. Pedro Laureano de los Reyes Macharé (Macheré) Chumbi Saguaraura Ynga". ${ }^{16}$

Pedro Laureano de los Reyes, Caballero de la Real Medalla, Coronel -fue primero capitán, luego teniente coronel, hasta llegar a su puesto actual- del Regimiento de Infantería de Indios de la ciudad de Lima, decía ser descendiente legítimo por ambas líneas de Huayna Capac. Como muchos otros, él también invocó las reales cédulas de privilegios concedidas por Carlos $V$ en 9 de mayo de 1544 y Felipe II en 15 de julio de 1573, que en su caso figuran apeladas a favor de don Pedro Chumbi Saguaraura y Guachaga (Guachaca) Ynga, su abuelo materno. Este Chumbi obtuvo provisión del virrey Marqués de Villagarcía en 6 de diciembre de 1738 confirmando ser descendiente de don Luis Guamán Paucar -quien será el tronco arquetípico- a quien se benefició con las mercedes de aquellas Reales Cédulas primigenias como descendiente de Huayna Capac.

Pedro Laureano pedía que se le declare "indio noble, fiel vasallo y buen cristiano", y en virtud de lo cual quedara exento de tributos, servicios, mitas y otros gravámenes, a favor suyo y de sus descendientes y una remuneración correspondiente a sus méritos. Aunque tanto la contaduría como el fiscal opinaron que no acreditaba con documentos necesarios la legítima descendencia que se atribuía ni los privilegios que dice se le atribuyeron a aquellos ascendientes, sólo se podía tener presente sus propios méritos y considerar válido lo que se le aprobó al abuelo materno, en cuyo caso podía consultarse el pedido favorablemente. El Consejo de Indias, a donde se remitió, opinó que había que ampararlo en la nobleza de que se hallaba en posesión y avisar se le atienda en todo lo que se pueda y permita, pero que si volvía a pedir algo, se le advirtiera lo hiciera en la Audiencia donde se le haría justicia.

Hasta aquí, la hoja resumen con el acuerdo final del Consejo de 28 de enero de 1777 de donde dimanó la real cédula de 19 de febrero de 1777 cuya minuta también viene inclusa en otro expediente, muy rico en información sobre el personaje, que encontré luego gracias a la primera pista con la que me topé aquella vez que conocí a Pedro Laureano.

15 CAHILL, David. Primus inter pares. La búsqueda del Marquesado de Oropesa camino a la gran rebelión (1741-1780). Revista Andina. 2003, n. 37, pp. 9-35. ROWE, John. Genealogía y rebelión. Algunos antecedentes de la sublevación de José Gabriel Thupa Amaru. Histórica. 1982, n. Vl/1, pp. 65-85.

${ }^{16} \mathrm{AGI}$, Lima 886, N 35 (1777). Toda la información que sigue se encuentra en este expediente. 
Pero ese acuerdo final tuvo una pequeña historia, que incluyó los documentos que como un archivo o programa personal había conseguido reunir el pretendiente. El 27 de julio de 1776 el Consejo vio la aludida real orden del 23 de julio que remitía el memorial de nuestro personaje. Con antecedentes, se debía mandar a la contaduría y al fiscal. La secretaría dijo sin embargo que no había hallado antecedentes. La contaduría respondió el 13 de diciembre 1777 y el fiscal en 24 de enero 1777.

En la instancia que originó el expediente, según el largo extracto que hizo la contaduría, además de lo dicho, señaló los siguientes renglones centrales del argumento genealógico. Que su abuelo paterno don Pedro de los Reyes Macheré sirvió en el año 1708 de piloto en el navío Jesús María que salió del puerto del Callao en corso de unos ingleses que hicieron fuga de la cárcel, a los cuales apresaron. Por este mérito y justificación de ser indio noble, el virrey Marqués de Villagarcía lo declaró el 1 de abril de 1739 por "indio principal" mandando que se le guarden los privilegios que le correspondían y quedara exento él y sus descendientes de servicios comunes salvo el de tributos, para lo que consiguió particular recomendación del Consejo en carta de 5 de mayo de 1737.

Frente al bastante modesto y pedestre mérito del abuelo paterno, por línea materna, el pretendiente sí que tenía un potente argumento. Don Luis Guaman Paucar Ynga, su tronco arquetípico y ascendiente por línea materna, consiguió de Carlos V la gracia y merced de poder traer y tener él y sus sucesores un escudo de armas de la manera que se contiene en la provisión de Valladolid en 9 de mayo de 1544 y Felipe II por otra expedida en 15 de julio de 1573, declaró al citado don Luis por descendiente de Guaynacapac Ynga, mandando que a todos los indios que constare y pareciere ser hijos y descendientes de este, se les dejase vivir libremente donde estuviesen, sin que pagasen tributos ni otros servicios.

Seguía el extracto del expediente señalando que estuvieron en el goce y posesión de estos privilegios cerca de dos siglos los sucesores, hasta que por los años de 1718, con motivo del lamentable estrago de peste y hambruna acaecido en la ciudad del Cuzco, se perdieron los papeles e instrumentos que eran la defensa de la casa de Guayna Capac, pero habiéndose encontrado por dicha casa los dos referidos documentos, ocurrió don Pedro Chumbi Saguaraura y Guachaga Ynga, abuelo materno del suplicante ante el referido virrey Villagarcía quien, en su vista y justificación de diez testigos examinados en Cuzco, conformándose con el parecer de ambos fiscales, declaró a Pedro por Ynga y legítimo descendiente de la Real estirpe del emperador Guayna Capac y como tal se le guardasen los privilegios que mandaba la Real provisión expedida a favor de Luis Guaman Paucar. Así, fue Pedro Chumbi, el abuelo materno, el que gestionó la validez de la ascendencia cuya justificación documental había quedado en vilo. Pero para que Pedro presentara sus papeles ante el virrey, antes hizo una serie de audaces movimientos tanto de viajes como de probanzas judiciales.

Esas eran las ramas del linaje, una muy modesta y otra, la más importante, a la que se acogieron varios linajes de supuestos incas. Luego el expediente se detiene en los méritos de nuestro Pero Laureano. El suplicante se había empleado desde su tierna edad en el Real servicio, desde 1740 hasta 1744 en el navío que salió del 
puerto del Callao por toda la costa a expulsar al enemigo inglés que se empleaba en el robo de Paita, por lo que fue honrado en 1758 con el título de Capitán de Infantería de los naturales de la provincia de Quito. Luego, en 1760, cuando se prestó el juramento de fidelidad a la Real persona de Su Majestad en la ciudad de Lima, comandó el batallón como capitán más antiguo, por lo que se confirió el 6 de septiembre de 1761 la tenencia coronela del tercio del batallón de naturales de que era capitán. Después, para la celebración del regocijo que manifestó dicha ciudad de Lima al tiempo de la coronación del rey, fue elegido por uno de los seis comisarios, en cuyo encargo se esmeró con las mayores demostraciones, pues además de haber exhibido aquella prorrata que le correspondió por razón de su gremio, se hizo cargo de vestir al niño que representaba a la Real persona a sus propias expensas, formándole la corona y cetro de piedras y perlas preciosas del mayor valor.

Según el archivo de Pedro Laureano, desde que mereció el primer empleo en la milicia, procuró desempeñar los encargos que se pusieron a su cuidado, con la fidelidad que corresponde a su lealtad y así, cuando por ausencia del maestre de campo del tercio de "infantería índica" se le encargó el entero de los respectivos hombres de fajina que concurren de orden de aquel virrey a la fortificación del presidio del Callao, cumplió exactamente con esta obligación, como lo informó el sargento mayor Marqués de Salinas en 20 de octubre de 1769. Luego, desde 19 de diciembre de 1772 se le concedió el título de coronel del referido regimiento y desde su ingreso en este honroso empleo ha sido su principal atención el arreglo de la tropa, no sólo en la disciplina militar sino en el reparo, decencia y lucimiento de todo el regimiento, costeando de su bolsillo los adherentes que por el uso continuo experimentaban deterioro, con otros gastos en arreglar las banderas que sirven en los alardes públicos, concurriendo también a la enseñanza de tambores y pífanos, buscando sujetos a propósito de la misma nación.

Por todo lo cual y porque por Real Cédula de 1774 "está prevenido que los oficiales reales de la ciudad de Lima ocurran con la justificación de sus méritos a pretender los empleos a que fueren proporcionados, concediendo dos años de término para que lo puedan ejecutar sin los informes de los superiores", suplica la merced que ya señalamos en el resumen inicial.

La contaduría extractó la Real Cédula de 1544 que decía que Guaman Paucar era descendiente de Guayna Capac y se le concedieron por armas un escudo hecho de dos partes, que en la una de ellas estuviese un águila negra rapante en campo de oro y a los lados dos palomas verdes; y en la otra parte, debajo, un tigre de su color y encima de él una borla colorada, que solía tener por armasita, y a los lados del dicho tigre dos culebras coronadas de oro en campo azul, y por orla unas letras que dijesen Ave María, y entre medias de las letras ocho cruces de oro de Jerusalén en campo colorado y por libel un yelmo cerrado, y por divisa un águila negra rapante con sus tres colores; y dependencias a follajes de azul y oro.

La Real provisión expedida en 15 de julio de 1573 por la Real Audiencia de Lima, reconoció que habiendo ocurrido a ella Guaman Paucar, haciendo presente que en aquellas provincias había muchos nietos y bisnietos y descendientes de Guaynacapac Ynga que vivían y se sustentaban de algunas chácaras y tierras que 
les dejaron sus padres y los caciques principales de dichas provincias los hacían tributarios y compelían a que fueran a servir, se mandó que a estos indios los dejasen vivir libremente donde estuviesen sin que pagasen tributos ni otros servicios ${ }^{17}$.

Esos documentos, que se "salvaron", son similares a otros que está constatado presentaron otras líneas de descendencia incaica y que tienen visos de verosimilitud. En 1738 se presentó ante el virrey el abuelo materno, que era natural del Cuzco, diciendo descendía de Luis Guaman Paucar que era bisnieto de Guayna Capac y se le amparó dicha pretensión como hemos señalado.

Mientras el abuelo Pedro Chumbi hacía sus gestiones el mismo virrey Villagarcía el 1 de abril de 1739 libró despacho a favor del padre del pretendiente, Josep de los Reyes Macheré, declarándolo indio noble, como descendiente de estirpe noble y calificada del pueblo de Colán, quedando libre de servicios salvo el tributo. Esto provino de la llegada de la carta de acuerdo del Consejo por D Miguel de Villanueva en 5 de mayo de 1737, donde haciendo relación de lo representado por Macharé y principalmente haber servido por más de 20 años el oficio de sacristán del pueblo de Colán, sin renta ni salario alguno, lo recomendó al virrey para que lo atendiera y consolase en su pretensión en lo que pudiera y no tuviera inconveniente. Como se ve, otro mérito de modesta calidad en la rama paterna.

Esos eran según el extracto los argumentos principales del Memorial de Laureano que firmó por poder en Madrid en 18 de junio de 1776 Josep García Riofrío. Ese extraordinario documento añade más carne al sustento de la historia genealógica que tejía gran parte del territorio andino. Allí Pedro Laureano se nomina con sus dos apellidos, de los Reyes Macharé o Macheré, caballero de la Real Medalla y Coronel del batallón de Lima y vecino allí. Nos da como dato nuevo que la madre se llamó Juana Chumbi Tito. Nieto por línea paterna de Pedro de los Reyes Macheré y D. Inés Andrea y por la materna de D. Pedro Chumbi y Da. María Tito. El abuelo fue hijo de Francisco Chumbi y Petronila Guachaca (Guachaga). Francisco hijo de D. Francisco Chumbi Sinchi y Da. María Saguaraura y este Chumbi Sinchi de D. Pedro Chumbi Saguaraura Ynga, descendiente de D. Luis Guaman Paucar Ynga, quien lo fue del emperador Guayna Capac.

El abuelo Pedro de los Reyes Macheré fue el que sirvió de piloto en 1708 en el navío Jesús María que persiguió desde el Callao a los ingleses que fugaron de Lima e infestaban y robaban la costa del sur, a los que apresaron en una piragua en la isla El Amortajado. Por eso y su justificada nobleza, consiguió el padre Josep lo declararan en 1739 indio principal y que se le guardasen los privilegios correspondientes. Y refiere la otra carta de recomendación de 1737.

\footnotetext{
17 Esta fue una sonada gestión y pleito judicial que los incas llevaron adelante para defender sus fueros. Alli aparece Juan Paucar Guaman según los documentos que explora ROWE, John. Probanza de los incas nietos de conquistadores. Histórica. 1985, n. IX/2, pp. 193-245. Más recientemente, DE PUENTE LUNA, José de la. Incas pecheros y caballeros hidalgos: la desintegración del orden incaico y la génesis de la nobleza incaica colonial en el Cuzco del siglo XVI. Revista Andina. 2016, n. 54, pp. 9-63, revisa lujosamente este pleito; allí figura, por lo menos tangencialmente un Luis Ynga Paucar.
} 
Como vimos, el primer nombramiento a que se hizo acreedor el suplicante fue de capitán de Infantería de los naturales de la Provincia de Quito, ciudad de Piura y puerto de Paita y Colán, en virtud del informe que hizo el Comandante Gobernador del Callao e inspector de milicias D. Francisco del Moral. En lo del juramento de fidelidad de 1760 cuando comandó el batallón que salió en alarde como capitán más antiguo, precedió a ese fin un decreto del gobierno por la discordia y disputa que hubo entre los capitanes de las seis compañías que salieron para esta Real función, sobre cuál había de mandar por razón de antigüedad. El cargo de Teniente Coronel del tercio del batallón de naturales del que era capitán, lo solicitó y obtuvo por informe que hizo D. Pedro de Segura y Zárate.

Dice Pedro Laureano en lo del regocijo de la coronación, que fue elegido por uno de los seis comisarios, y que para tal desempeño era preciso lo fuesen de la mayor nobleza de aquel reino. La corona y cetro de piedras preciosas y perlas del mayor valor, no bajaron, según la estimación de los más prudentes lapidarios, de 100,000 pesos, exponiéndose al lasto de cualquier piedra o perla que se hubiese perdido. Como capitán que era entonces, concurrió a la recaudación voluntaria de prorrata, "que cada uno se impuso a esfuerzos de su amor, con lo cual se ejecutó la más lucida y vistosa función que se vio jamás en aquella América meridional", como así lo informó el corregidor de dicha ciudad de Lima a instancia del que suplica y por mandato de aquel virrey en 28 de noviembre de $1764^{18}$.

Para ascender a coronel, informó favorablemente el maestre de campo del batallón de milicias de la ciudad, D. Feliz Morales de Aramburu y mereció se le recomendase el particular mérito de la jura que se hizo para la exaltación al trono que ya refirió.

Remata un traslado de los Autos que, ante el alcalde ordinario de Lima D. Sebastián de Aliaga y Colmenares, se iniciaron en 2 de marzo de 1775 para legalizar la documentación acreditativa de la representación de Laureano. Transcribe y legaliza todas las piezas de su relato. Va firmada del escribano Joeph Silverio Ascarrunz en 6 de abril de 1775. Está anotada al dorso como adjunta con el memorial remitido con la Real Orden de 23 de julio de 1776. Adjunto un poder de Pedro Laureano de los Reyes Machare Chumbi Saguaraura Ynga, caballero de la Real medalla, coronel del regimiento de naturales de Lima, otorgado en 14 de noviembre de 1775 a Joseph García de Riofrío, vecino de Madrid, para presentar memoriales y pedir mercedes.

La certificación del escribano se hace sobre la documentación contenida en otra certificación que fue sacada en Cuzco el 30 de enero de 1732 por Pedro Chumbi Saguaraura Inga de la Real Provisión de 1573 obtenida a pedido de Luis Guaman Paucar a favor de los descendientes de Guayna Capac, presentada para su validación por Pedro Chumbi Saguaraura Ynga, hijo legítimo de Francisco Chumbi Sahuaraura Ynga y doña Petrona Guachaca, descendientes legítimos de Guayna capac. Autos en Cuzco a 30 de enero de 1732. Adjunta a esta, la cédula fundacional del emperador Carlos V de 9 de mayo de 1544 a favor de Luis Guaman Paucar.

${ }^{18}$ Se trataba de las fiestas de Lima por la coronación de Carlos III en 1760. 
Hubo en el camino unos descendientes que cuidaron mantener válidas las mercedes del siglo XVI. Esta Real Provisión de 1573 concuerda con otra que está inserta en una Provisión Real despachada por los señores presidente y oidores de Lima en 12 de mayo de 1650 y de pedimento de D. Sebastian Gualpa Roca, se dio esta en Lima en 17 de junio de 1651. Concuerda con el traslado de donde se sacó este y que exhibieron D. Luis Guaman Paucar Ynga y D. Martín Guamán Paucar Ynga, principales de Suriti de la provincia de Abancay, en Cuzco a 12 de diciembre de 1583 ante Pedro López de la Cerda escribano. Concuerda el traslado de la Real Provisión de 1573, comprobado en 1583 ante el escribano referido, que exhibió Pedro Chumbi Sauaraura Ynga en Cuzco en 10 de febrero de 1732. El archivo familiar indígena era de vital importancia para mantener viva la memoria familiar y para gestionar mercedes ante las autoridades.

Como señalamos, hubo un bache en la continuidad de la posesión del linaje, que hubo de subsanar el abuelo materno de Pedro Laureano en 1732. Pedro Chumbi Saguaraura y Guachaca Ynga, expresó que "con motivo del lamentable estrago y fatal ruina que generalmente padeció el Cuzco en 1718, con hambres y otras pestes que la dejaron casi asolada, se perdieron los papeles e instrumentos que eran el Broquel y la defensa toda de la familia de Guaynacapac y su noble descendencia". Entre dichos papeles se hallaban los pertenecientes a D. Luis Guaman Paucar a quien se premió con sucesivas cédulas de las que sólo se mantiene el testimonio de la provisión de 1573 comprobada en 1583 que presenta certificada. Instrumento suficiente, incluso frente a los perdidos, para conservar los derechos de su casa. Restaba probar que él era descendiente por ambas líneas de la sangre del Ynga Guaynacapac, como lo era de Luis Guaman Paucar, declarado por tal en la provisión presentada. Para ello se hizo probanza. Los testigos que presentó serían preguntados por el tenor de las siguientes preguntas:

Si conocían a D. Pedro Chumbi Saguaraura y a Da. Petrona Guachaca y Ayquipa y a su marido D. Francisco Chumbi Saguaraura. Si conocieron a D. Francisco Chumbi Sinchi el viejo y Da. María Sahuaraura. Si el viejo y la Saguaraura procrearon a Francisco el mozo que, a su vez, casado con la Guachaca tuvo a Pedro.

Si sabían y habían oído a los indios Yngas así antiguos y viejos como a los presentes que los mencionados son descendientes por línea recta de varón de la casa y familia de Gaynacapac y que esto constaba y parecía de la probanza antigua que hizo su abuelo don Francisco Chumbi de su prosapia y genealogía, cuyos papeles y documentos fueron notoriamente vistos en esta ciudad.

Si habían sido respetados y venerados como tales descendientes y los corregidores no los habían inquietado con tributos y servicios.

Si sabían que sus antecesores siempre se habían empleado en cargos de lustre y honor, ya de cacicazgos, ya de gobernadores, mayores y principales de estas provincias e inmediaciones.

Si sabían que sus mayores habían sido las primeras personas y caciques de estas siete parroquias y en calidad y representación de alférez real han sacado 
siempre el estandarte real el día del apóstol Santiago para asistir a la solemne fiesta que este día se hace en la catedral en memoria de la conquista de estos dominios.

Si sus mayores habían sido siempre los primeros y más prontos en el real servicio, ofreciendo en casos oportunos sus personas y facultades.

El interrogatorio es una pieza extensa llena de detalles del mayor interés, que ahora no podemos resumir. Desfilaron ante el juez nombrado los caciques principales y mayores de las parroquias de San Gerónimo, San Sebastián, San Blas, Santiago, Hospital y Belén que no ofrecieron contradicción alguna al linaje de Pedro. Finalmente, un domingo de julio en la parroquia de Santa Ana, el escribano, por interpretación de don Sebastián Gualpa, mayor y principal, hizo saber el contenido del auto a los mandones y principales quienes de su parte y la del común no tuvieron tampoco que oponer nada en contra pues vivían satisfechos de ser Pedro hijo de Francisco Chumbi Saguaraura y de Petrona Ayquipa Guachaca y así sucesivamente siendo descendientes legítimos de Guayna Capac.

Luego de estas declaraciones colectivas y generales, se presentaron los testigos más interesantes. Cada uno dio algún retazo de la memoria de este linaje. Veamos sólo uno, el de don Francisco de Mendoza, vecino de 92 años. Entre las respuestas a las varias preguntas, dejó el testimonio de la historia de la ausencia del interesado Pedro Chumbi. Conocía a Pedro desde que nació y conoció hasta sus abuelos que "fueron yngas principales en las provincias anexas a este obispado". Dice saber mucho de la antigüedad, confirma todo y dice que el lugar donde se comentaba más esto era en la provincia de Abancay y Aymaraes. Dice que Don Francisco Chumbi Sinchi el viejo probó plenamente ser nieto y legítimo descendiente del famoso Ynga Don Luis Guaman Paucar y de la generación de Aposinche, bisabuelo de don Gabriel Sinchi, "que estos papeles e instrumentos los tuvo varias veces el testigo en su mano porque gustaba imponerse en la serie y sucesión de aquellos emperadores y reyes del Perú" por los cuales sabía que Francisco Chumbi Sinchi el viejo era legítimo descendiente de Luis Guaman Paucar y Gabriel Sinchi, ambos descendientes inmediatos del emperador Guayna capac. Dice que estos papeles cayeron en poder de Francisco Chumbi Saguaraura que no dio razón de su paradero de manera que ahora sólo corre el testimonio de la provisión y cédula referida, "cuya falta cede en perjuicio de la familia, porque de aquí a algunos años, no habiendo ya vecinos contemporáneos que declaren haberlos conocido, ni instrumentos con que calificarlo, se oscurecerá y perderá enteramente la descendencia. Y así el testigo, por caridad y amor a los emperadores Yngas de el Perú, porque no se ocultase en sus legítimos descendientes tan ilustre sangre..." siempre instó a los parientes de esta casa a que supliesen la falta de aquellos instrumentos con información plena de testigos que hubiesen conocido a sus antepasados y nietos de don Luis Guaman Paucar y legítimos descendientes de la casa de Aposinchi, bisabuelo de don Gabriel Sinchi. Y ahora, Don Pedro Chumbi Saguaraura Guachaca, al cabo de veinte y tantos años que faltaba de esta ciudad por haberse ausentado con el fin de viajar a los reinos de España, promovía tan importante asunto y glorioso para su posteridad, dando esta información que sirva en delante de escudo para sostener en su antiguo honor los derechos de la casa y familia. Sabe que este don Pedro está casado en los términos de la jurisdicción de Piura con Da. María Tito y Inquiltupa, en quien 
tenía una hija nombrada Da. Juana Chumbi Tito, casada con D. Joseph Reyes Machari, principal de Colan, lo que había oído decir tanto a Pedro Chumbi como a Felipe Rivas que vino desde Piura en compañía de Chumbi. Dice que "cuando Don Pedro Chumbi se ausentó para los reinos de España a presenciarse ante el Rey Nuestro Señor y besarle sus Reales pies, fue muy sensible su ausencia, y no llegó a verificarse su embarque por la razón que lleva dada el testigo en la deposición cuarta". Es decir, porque se asentó en Colán-Piura donde se casó.

El 2 de mayo de 1738 Pedro hizo ratificar ante el virrey marqués de Villagarcía su información de nobleza. Los pareceres favorables del fiscal y fiscal protector llevan fecha de 28 de mayo y 3 de agosto de 1738. La provisión del virrey el 6 de octubre de ese año. El traslado de la provisión lo hizo sacar en Cuzco Pablo Saguaraura inmediatamente después.

Como se puede apreciar, en la historia de este linaje, que unía al tronco incaico varios de los potentes cacicazgos de la región, como los Guachaca y los Ayquipa, hay en un momento una "pérdida" de la historia que se subsana con la memoria de los testigos, que hacen así un recuerdo coral de la historia en interés del pretendiente, pero también del colectivo indio ${ }^{19}$. Pedro el abuelo de nuestro personaje, viajaba a la metrópoli, como muchos otros, premunido de sus pocos papeles "salvados" de una tragedia, en este caso el hambre y peste de la ciudad, en otros casos, naufragios o asaltos, todos dispuestos a mostrar sus honorables orígenes y obtener mercedes, por muy modestas que pareciesen, iban también en busca del honor. Pero el viajero se quedó sólo al inicio de su largo viaje y se afincó en un espacio diferente, en el norte costeño donde se entroncó con un linaje local a través de la mujer María Tito Inquiltupa. Su hija, Juana Chumbi Tito es quien se enlaza con el modesto linaje de Colán, Macheré por línea masculina y Muyalepe por la femenina. Pero Laureano también se esforzó por documentar, con relatos de servicios militares en el océano y servicios religiosos en la iglesia pueblerina. Pero otra "pérdida" se suscitó a la vuelta del segundo viaje en pos de la memoria de Pedro Chumbi. Una vez certificada la veracidad de su linaje, con el interrogatorio practicado en Cuzco y la certificación ante el virrey en Lima, para poder amparar a su nueva familia piurana, el descendiente de los incas chumbis falleció sin llegar a su destino. Pedro Laureano subsanó la falta con otra información que se tomó en Colán en 6 de abril de 1761, por el apoderado ante el corregidor de Piura.

El empeño documental de Pedro Laureano iba dando frutos mientras continuaba con sus propios servicios para la hoja de méritos. Así obtuvo el título de teniente coronel. En 1761 hizo exhibición de sus servicios desde 1744 en el navío que salió del Callao por toda la costa a "expulsar al enemigo inglés sobre el robo de Paita en que fue por comandante Pedro de Madranda, heredando su leal servicio de su abuelo Pedro de Macheré que también sirvió de piloto en el navío que se dispuso de corso para contrarrestar al enemigo inglés que andaba haciendo daño en estos mares hasta lograr apresar ese navío lo que le mereció la benignidad de Su Majestad". Luego el mérito de haber llevado el suplicante el comando de las seis compañías que se señalaron para la función de la marcha que se hizo para la jura

\footnotetext{
${ }^{19}$ Sobre los linajes Guachaca o Ayquipa y otros en Cuzco, ver GARRET, David. Sombras del imperio. La nobleza indígena del Cuzco, 1750-1825. Lima: Instituto de Estudios Peruanos, 2009.
} 
de su majestad, con todo el esplendor y lucimiento que es notorio. Así se expresó sobre este mérito en un memorial:

\begin{abstract}
"Don Laureano de los Reyes, teniente coronel del regimiento de naturales del batallón de esta ciudad... dice que además del servicio que ha hecho en el empleo de tal teniente coronel, sirviéndolo con aquella exactitud y vigilancia que es notoria, también ha servido en otros empleos de la Nación Indica, que fue el que ejecutó en las fiestas reales que se hicieron a la coronación de nuestro rey en que fuera de haber hecho otros servicios, se hizo cargo de vestir a nuestro rey y señor a su costa, el que ojos faltaban para ver la grandeza y riqueza que llevaba, corona imperial, peto y todo lo demás, como que fue nombrado por uno de los primeros comisarios de dichas fiestas reales, que todo estuvo a su cuidado, junto con los demás comisarios que fueron nombrados y todos los naturales que existen en esta corte dieron sus prorratas según sus posibles de cada uno con mucho amor. Para el acompañamiento de dicho carro salieron muchas danzas cantando y victoriando la exaltación de nuestro rey y señor dentro de dicho carro en la plaza con su embajador, que lo fue don Francisco Humac Minoyulli, que a su costa hizo esta salida; como también salieron los comisarios a caballo, vestidos de uniforme en que consumió y gastó crecidos pesos que puso de su peculio. $Y$ para que todo esto conste, se ha de servir... mandar que el general Justino de Solórzano, corregidor y justicia mayor que fue de esta ciudad en aquel tiempo, certifique todo lo acaecido y obrado en el asunto...".
\end{abstract}

Lo que efectivamente practicó el 27 de octubre de 1764, certificando haber convocado al Cabildo justicia y regimiento de naturales de la ciudad y a "todos los oficiales militares de plana mayor" en la sala de Copacabana propia de dichos naturales, donde se resolvió se hicieran unos fuegos e iluminación general , un día de toros y otro de carro, eligiendo seis comisarios de la nación, uno de los cuales Laureano encargado de vestir al niño que representaba a Su Majestad formando la corona, cetro de las perlas y piedras preciosas que no bajó de cien mil pesos, y recolectó la prorrata al cabo de lo cual se ejecutó "la más lucida y costosa función que hasta ahora se ha visto en esta América meridional".

Así se entiende su afán de 1758 cuando se preparaba la fiesta, cuando a su instancia se siguieron unos autos, en que descubrimos que este descendiente de los reyes del Perú era un maestro zapatero y entonces segundo mayordomo -luego sería mayordomo- de la cofradía de indios de Nuestra Señora de la Candelaria (convento de San Francisco), para que se le permitiera guardar en su casa las alhajas que adornaban la imagen del Santo Cristo de la Agonía, propiedad de la cofradía. Las joyas que sirvieron para adornar aquella imagen de que tanto se preciaba $^{20}$.

20 CAMPOS, Javier y FERNÁNDEZ DE SEVILLA (ed.). Catálogo de cofradías del Archivo del Arzobispado de Lima. San Lorenzo del Escorial: Instituto Escurialense de Investigaciones Históricas y Artísticas, 2014. 1758 Lima, Autos seguidos por Laureano de los Reyes Macharí, maestro zapatero y segundo mayordomo de la ofradía de indios de Nuestra Señora de la Candelaria (convento de San Francisco), para que se le permita guardar en su casa las alhajas que adornan la imagen del Santo Cristo de la Agonía, propiedad de la cofradía. 1761 Lima. Autos seguidos sobre las cuentas presentadas por el capitán don Laureano de los Reyes del tiempo que fue mayordomo de la cofradía de indios de Nuestra Señora de la Candelaria (convento de San Francisco), desde 1760 hasta 1761. AGI, Lima 891. 
Con esos méritos y finalmente "no omitiendo el suplicante recomendar a vuexcelencia el honroso esmalte de su noble nacimiento, pues es descendiente el suplicante de indios nobles y principales". Pidió la merced de ser nombrado por coronel del tercio del batallón de los referidos naturales, "al ejemplar y modelo que se acostumbra en las milicias de los reinos de España".

Luego, el 16 de octubre de 1769, Laureano informó al virrey que había cumplido con el mandado que se le hizo, en ausencia del maestre de campo del "tercio de infantería índica", coronel don Antonio Blas Tuñoque, de enterar los respectivos hombres que con título de fajina concurren a la fortificación del presidio del Callao, concluyendo el último turno el quince del corriente mes de octubre.

Hasta que por fin obtuvo el título de coronel por Manuel Amat por estar vaco el empleo de coronel del tercio de infantería de naturales por muerte del que lo obtenía, el 19 de diciembre de 1771. Pero siguió presentando méritos, haciendo certificaciones y memoriales hasta el que elevó al Consejo de Indias con el que empezamos esta parte del estudio.

No era Pedro Laureano el único que se afanó por mostrar que también era un inca. Sabemos de muchos otros que de distintas maneras lo buscaron, con mayor o menor fortuna, con mayores o menores argumentos. Entre ellos tejieron alianzas, pero también enfrentamientos por competencia. Todos los indicios lo hacen un hombre leal a la corona, pero también celoso guardián de la memoria de la nación índica, a la que representaba desde su posición de militar, de cófrade y de honroso descendiente de indios nobles.

Cuando se desbarató el alzamiento que quiso llevar adelante en Huarochirí en 1781 Felipe Velasco Tupac Inca, que fue capturado en 1780 entre los sospechosos de haberse vinculado con José Gabriel Tupac Amaru cuando estuvo en Lima pleiteando por el marquesado de Oropesa y ya pensando en su general sublevación, también fue capturado un indígena letrado, también cófrade, de oficio sastre, llamado Felipe González Rimay Cochachín. Entre los papeles de su archivo, pues estos naturales letrados tenían un archivo, parte del archivo de la nación, apareció el nombre de Pedro Laureano ${ }^{21}$. Los investigadores no pudieron entender por qué ni lograron probar nada, pero el testimonio declaración del negro tamalero llamado Felipe Humeres que vio a Tupac Amaru en 1778 con tercianas durante su estancia en Lima fue muy claro. Declaraba que visitaba al inca rebelde un indio zapatero maestre de campo, sin duda se trataba de Pedro Laureano ${ }^{22}$. Allí tenían tertulias en las que se debatiría sobre la nobleza de los incas y la licitud de reclamar sus honores, privilegios y mercedes, sobre el incumplimiento de un trato tácito con la corona, sobre los abusos que se cometían y la marginación y desprecio que sentían a pesar de su nobleza y servicios.

No hay duda, Pedro Laureano, tan vigilante en su servicio al rey y a su historia personal que lo anclaba con la vieja monarquía incaica, participó de juntas que tuvieron al inca Tupac Amaru en el centro de las conversaciones. El escribano de las

\footnotetext{
21 AGI, Lima, 1047.

22 AGl, Lima, 1042.
} 
causas contra Mariano Tupac Amaru, Andrés Mendigure, el cacique Manuel Perfecto Llacsa, Mariano Barrera y el cacique Simbrón Pacheco fue don Clemente Castellanos, que lo fue también de la residencia del virrey Guirior. Había actuado antes en diciembre de 1774 en la causa que siguió Juan Joseph de la Puente Ibáñez, alcalde del crimen, en la averiguación y castigo de un tumulto en Guamachuco. Era hermano del ermitaño agustino fray Gabriel Castellanos que fue quien denunció por una confesión que recibió, la intentada sublevación contra las aduanas que se fraguaba en Cuzco en 1780. Actuó también con el oidor Manuel de Mancilla muchas diligencias a principios de la sublevación de José Gabriel Tupac Amaru, sirviendo con puntualidad de tal modo que una noche fue con tropa al pueblo de Miraflores a traer preso a Pedro Laureano de los Reyes, coronel del regimiento de indios a quien se le consideró culpado, habiendo hecho de regreso el reconocimiento de los papeles que se le hallaron -jefectivamente Pedro Laureano tenía un archivo!- leyéndolos hasta el amanecer ${ }^{23}$. También actuó con el Marqués de Corpa, encargado para el mismo fin para la captura de Miguel Montiel, confidente del rebelde.

No sabemos por qué no fue condenado Pedro Laureano, probablemente por su edad, por alguna de sus redes personales que tan bien tejió y pudo favorecerlo o su avanzada edad por la que al poco falleció. Lo cierto es que pare entonces, entrando al final del siglo XVIII, todos estos actores de la nación índica, de distintas maneras y con diferentes objetivos, aliados o enfrentados, confabulados de manera explícita o simplemente como curiosos o compañeros de ruta, estaban, para serlo o para tenerlo, buscando un inca ${ }^{24}$.

\section{Bibliografía}

BRENDECKE, Arndt. Imperio e información. Funciones del saber en el dominio colonial español. Madrid: Iberoamericana; Frankfurt am Main: Vervuert, 2012.

BURNS, Kathryn. Making Indigenous Archives: the Quilcaycamayoq in Colonial Cuzco. En: RAMOS, Gabriela and YANNAKAKIS, Yanna (eds.). Indigenous Intellectuals. Knowledge, Power and Colonial Culture in México and the Andes. Durham: Duke University Press, 2014, pp. 237-260.

CAHILL, David. Primus inter pares. La búsqueda del Marquesado de Oropesa camino a la gran rebelión (1741-1780). Revista Andina. 2003, n. 37, pp. 9-35.

CAMPOS, Javier y FERNÁNDEZ DE SEVILLA (ed.). Catálogo de cofradías del Archivo del Arzobispado de Lima. San Lorenzo del Escorial: Instituto Escurialense de Investigaciones Históricas y Artísticas, 2014.

CASTRO FLORES, Nelson. Estrategias familiares, prácticas jurídicas y comunidad de memoria. Los descendientes de Tito Alonso Atauchi y Viracocha Inca en Charcas, siglos XVI-XVIII. Estudios Atacameños. 2019, n. 61, pp. 177-198.

\footnotetext{
${ }^{23}$ AGI, Lima, 598.

${ }^{24}$ En homenaje a FLORES GALINDO, Alberto. Buscando un Inca: identidad y utopía en los Andes. Lima: Instituto de Apoyo Agrario, 1987.
} 
CHOQUE CANQUI Roberto y GLAVE, Luis Miguel. Mita, caciques y mitayos: Gabriel Fernández Guarache. Memoriales en defensa de los indios y debate sobre la mita de Potosí (1646-1663). Sucre: Archivo y Biblioteca Nacionales de Bolivia, 2012.

CUNILL, Caroline. Archivos en los Pueblos Mayas de Yucatán y la Construcción de una Memoria Legal (siglo XVI). Fronteras de la historia. 2016, n. 21/1, pp. 14-39.

ESTRUCH, Dolores y OYARZABAL, María Cecilia. Indígenas y archivos. Entre el acervo documental y las herramientas metodológicas. El caso de Jujuy colonial. Revista Historia y Justicia. 2016, n. 7, pp. 95-121.

FLORES GALINDO, Alberto. Buscando un Inca: identidad y utopía en los Andes. Lima: Instituto de Apoyo Agrario, 1987.

GARRET, David. Sombras del imperio. La nobleza indígena del Cuzco, 1750-1825. Lima: Instituto de Estudios Peruanos, 2009.

GLAVE, Luis Miguel. La gestación de un programa político para la nación indiana (1645-1697). Revista Andina. 2018, n. 56, pp. 9-99.

GLAVE, Luis Miguel. Un curacazgo andino y la sociedad campesina del siglo XVII. La historia de Bartolomé Tupa Hallicalla, curaca de Asillo. Allpanchis. 1989, n. 33, pp. 11-39.

GLAVE, Luis Miguel. Memoria y memoriales: la formación de una liga indígena en Lima (1722-1732. Diálogo Andino. 2011, n. 37, pp. 5-24.

HONORES, Renzo. Los caciques y las pruebas: El uso de las testimoniales en las disputas por cacicazgos en la Audiencia de Lima, 1550-1610. En: Tucumán: XI Jornadas Interescuelas/Departamentos de Historia [en línea]. Departamento de Historia, Facultad de Filosofía y Letras. Universidad de Tucumán, 2007. Disponible en <http://cdsa.aacademica.org/000-108/924>.

JURADO, M. Carolina. Descendientes de los primeros. Las probanzas de méritos y servicios y la genealogía cacical, Audiencia de Charcas, 1574-1719. Revista de Indias. 2014, n. 261, pp. 387-422.

LIENHARD, Martin. Testimonios, cartas y manifiestos indígenas. Caracas: Biblioteca Ayacucho, 1992.

LÓPEZ BELTRÁN, Clara Estructura económica de una sociedad colonial: Charcas en el siglo XVIII. La Paz: CERES, 1988, pp. 271-275.

MATOS, Mar y ORTEGA, Moisés. Acolla informes para el pueblo y para el tiempo. Jauja: Holckon editores, 1999.

NAVARRO GALA, Rosario. El libro de protocolo del primer notario indígena (siglo $X V I)$. Cuestiones filológicas, discursivas y de contacto de lenguas. Madrid: 
Iberoamericana-Vervuet, 2015.

NOACK, Karoline. Los caciques ante el notario: transformaciones culturales en el siglo XVI. EN: NOEJOVICH CHERNOFF, Héctor (ed.). América bajo los Austrias: economía, cultura y sociedad. Lima: Pontificia Universidad Católica del Perú, 2001, pp. 199-200.

PUENTE LUNA, José de la. Incas pecheros y caballeros hidalgos: la desintegración del orden incaico y la génesis de la nobleza incaica colonial en el Cuzco del siglo XVI. Revista Andina. 2016, n. 54, pp. 9-63.

RAPPAPORT Joanne y CUMMINS, Tom. Más allá de la ciudad letrada: letramientos indígenas en los Andes. Bogotá: Editorial Universidad del Rosario, 2016.

ROBLES, Román y MARTíNEZ, Melinda. Sociedad y tradiciones en el valle de Yanamarca. Revista de Antropología (UNMSM). 2004, núm. 2/2, pp. 191-250.

ROWE, John. Genealogía y rebelión. Algunos antecedentes de la sublevación de José Gabriel Thupa Amaru. Histórica. 1982, n. VI/1, pp. 65-85.

ROWE, John. Probanza de los incas nietos de conquistadores. Histórica. 1985, n. IX/2, pp. 193-245. 